\title{
Effect of imposed strain and annealing temperature on uniform elongation in A5052 alloy processed by accumulative roll bonding
}

\author{
Keizo KASHIHARA*, Yoshikazu KOMI* and Nobuhiro TSUJI** \\ * National Institute of Technology, Wakayama College \\ 77 Noshima, Nada, Gobo, Wakayama 644-0023, Japan \\ E-mail: kashihara@wakayama-nct.ac.jp \\ ** Department of Materials Science and Engineering, Kyoto University \\ Yoshida Honmachi, Sakyo-ku, Kyoto 606-8501, Japan
}

Received 29 February 2016

\begin{abstract}
The relation between strain and uniform elongation, and the effect of low-temperature annealing, were examined using an Al-Mg alloy (A5052) processed by accumulative roll bonding (ARB). Specimens were deformed by ARB for 1 to 7 cycles at room temperature, and then subjected to isochronal annealing for $30 \mathrm{~min}$ at temperatures ranging from 100 to $300{ }^{\circ} \mathrm{C}$. Tensile properties, hardness, and grain boundary structure before and after annealing were investigated. The uniform elongation of ARB-processed specimens decreases with increasing ARB cycles. However, the elongation is improved by low-temperature annealing for specimens processed by ARB of 3 or more cycles. Higher strain in the ARB process results in higher uniform elongation after annealing, even though the specimens have the same value of $0.2 \%$ proof stress. This improvement of the uniform elongation by annealing is caused by annihilation of dislocations inside ultra-fine grains, which are developed by ARB of 3 or more cycles.
\end{abstract}

Key words : Aluminum-magnesium alloy, Severe plastic deformation, Mechanical property, Low temperature annealing, Ultrafine grains

\section{Introduction}

Aluminum alloy sheets and plates with high strength and good formability have been required for use as outer panels for automobiles. Severe plastic deformation (SPD) methods are very useful techniques to attain ultra-grain refinement which can strengthen plates without adding alloying elements. There are several SPD methods such as high pressure torsion (HPT) (Abdulov, et al., 1990) (Zhilyaev, et al., 2005), equal-channel angular pressing (ECAP) (Valiev, et al., 1991) (Furukawa, et al., 1996), cyclic extrusion and compression (CEC) (Richert and Korbel, 1997) (Richert, et al., 1999), and accumulative roll bonding (ARB) (Saito, et al., 1999) (Pirgazi, et al., 2008). Among these SPD methods, ARB method is especially notable for being capable of producing sheets and plates with large dimensions. As-ARB-processed sheets show extremely high strength, but poor elongation during tensile tests (Saito, et al., 1999).

Because Al-Mg alloys are not heat-treatable alloys but are generally strengthened by solid solution hardening and work hardening, there is a great interest in the hardening by ARB and softening by subsequent annealing.

There are several reports on the mechanical properties of ARB-processed Al-Mg alloys. For example, Tsuji et al. investigated the occurrence of super-plasticity in an A5083 alloy, which was processed by ARB to an equivalent strain of 4.0 at $200{ }^{\circ} \mathrm{C}$, and then deformed under tension at temperatures ranging from 200 to $400{ }^{\circ} \mathrm{C}$ (Tsuji et al., 1999). Toroghinejad et al. examined the structure, strength and ductility of an A5083 alloy processed by ARB to an equivalent strain of 4.8 at room temperature (Toroghinejad et al., 2013).

In our previous study, the relationship between tensile properties and microstructure changing in annealing was investigated for an Al-Mg alloy (A5052) processed to 7 cycles of ARB at room temperature (Kashihara et al., 2015). 
Interestingly, it was found that the specimen annealed at $200{ }^{\circ} \mathrm{C}$ after 7 cycles of ARB had the same $0.2 \%$ proof stress value but a larger uniform elongation than the specimen processed by 3 cycles of ARB. However, that study only reported the tensile properties in limited kinds of specimen, specifically, the specimen annealed after 7 cycles of ARB. In order to clarify the effect of strain imposed by ARB on the tensile properties after subsequent annealing, materials processed by various ARB cycles should be investigated.

The aim of this study is to understand how ARB-induced strain affects the uniform elongation after low-temperature annealing; the mechanical properties after annealing in A5052 alloy processed for 1 to 7 ARB cycles are examined.

\section{Experimental procedures}

Table 1 shows chemical composition of the commercial A5052 alloy used in the present study. Sheets of A5052 alloy with a thickness of $0.5 \mathrm{~mm}$, length of $120 \mathrm{~mm}$, and width of $30 \mathrm{~mm}$ were fully annealed at $345{ }^{\circ} \mathrm{C}$ for $30 \mathrm{~min}$. Figure 1 shows a grain structure of the sheet before ARB, measured by electron backscatter diffraction (EBSD) using a scanning electron microscope (JEOL JSM-6510 SEM); the EBSD step size was $1 \mu \mathrm{m}$. The structure was analyzed by orientation imaging microscopy software (TSL OIM-analysis). The starting material consisted of almost-equiaxed grains, and the average grain size was estimated to be $12.8 \mu \mathrm{m}$.

After degreasing and wire-brushing the contact surfaces, two sheets were stacked (1 mm total thickness) and roll-bonded to $0.5 \mathrm{~mm}$ thickness at room temperature, using a two-high rolling mill with a roll diameter of $70 \mathrm{~mm}$ without lubricant. The bonded sheet was cooled in water immediately after rolling. This process is denoted as " $1 \mathrm{cycle}$ of ARB”. Table 2 shows the relationship between the number of ARB cycles and corresponding equivalent strains. The ARB process was carried out up to 7 cycles in this study, corresponding to an equivalent strain of 5.6.

Table 1 Chemical composition of the A5052 alloy sheet studied (mass \%).

\begin{tabular}{c|c|c|c|c|c|c|c|c}
\hline \hline $\mathrm{Si}$ & $\mathrm{Fe}$ & $\mathrm{Cu}$ & $\mathrm{Mn}$ & $\mathrm{Mg}$ & $\mathrm{Cr}$ & $\mathrm{Zn}$ & $\mathrm{Ti}$ & $\mathrm{Al}$ \\
\hline 0.11 & 0.25 & 0.03 & 0.06 & 2.5 & 0.19 & 0.02 & 0.02 & Bal. \\
\hline
\end{tabular}

Table 2 Relationship between the number of ARB cycles and corresponding equivalent strains.

\begin{tabular}{c|c|c|c|c}
\hline \hline Number of ARB cycles & 1 & 3 & 5 & 7 \\
\hline Equivalent strain for thickness reduction & 0.8 & 2.4 & 4 & 5.6 \\
\hline
\end{tabular}
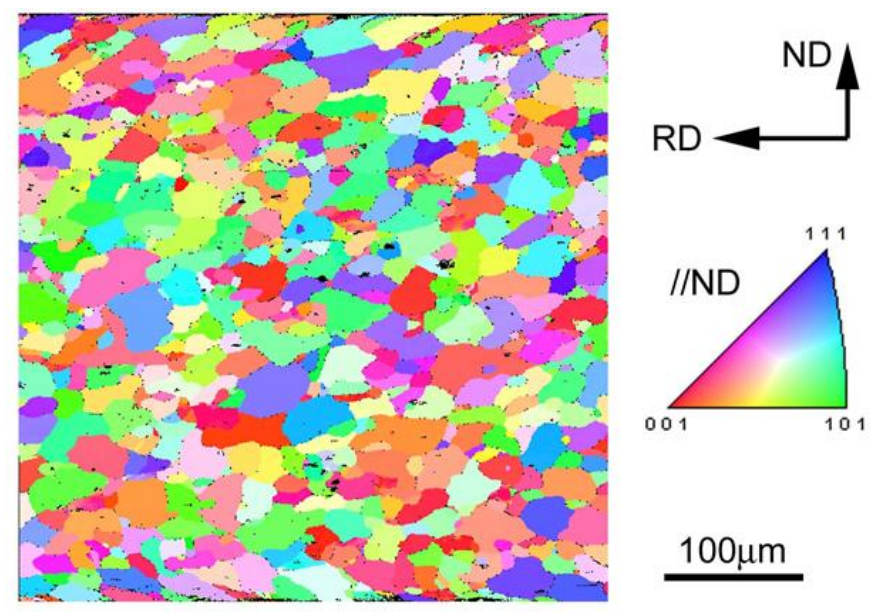

$100 \mu \mathrm{m}$

Fig. 1 An orientation image map on a longitudinal section of the starting material sheet measured by the electron backscatter diffraction (EBSD) method. Each grain is colored to indicate the crystal orientation parallel to the normal direction of the sheet, as shown by the color key. The symbols "RD" and "ND" mean the rolling direction and the normal direction, respectively. 
Tensile specimens were cut from the ARB-processed sheets using an electric discharge machine. The specimens after 1,3,5, and 7 ARB cycles were denoted as "specimens $1 c, 3 c, 5 c$, and $7 c$," respectively. The tensile specimens had a gage length of $10 \mathrm{~mm}$ and a width of $5 \mathrm{~mm}$, with the tensile axis parallel to the rolling direction of the sheet. Tensile tests were performed at an initial strain rate of $8.3 \times 10^{-4} \mathrm{~s}^{-1}$ at room temperature, and tensile strain was precisely measured by an extensometer. Two tensile tests were carried out for each specimen condition.

The specimens $1 \mathrm{c}, 3 \mathrm{c}, 5 \mathrm{c}$, and $7 \mathrm{c}$ were isochronally annealed for $30 \mathrm{~min}$ at temperatures ranging from 100 to $300{ }^{\circ} \mathrm{C}\left(50{ }^{\circ} \mathrm{C}\right.$ steps). The annealed specimens were then subjected to tensile tests under the same conditions as for the as-ARB-processed specimens. Specimen designations were amended appropriately; for example, the specimens processed to 5 cycles of $\mathrm{ARB}$ and then annealed at 100,200 , and $300{ }^{\circ} \mathrm{C}$ were called "specimens $5 c$-100, 5c-200, and $5 c-300$," respectively. Vickers hardness was measured for the ARB-processed and annealed specimens on a rolling plane under a load of $0.98 \mathrm{~N}$.

In order to estimate grain boundary spacing along the normal direction of the sheet, EBSD analysis was carried out for the ARB-processed and annealed specimens using a field-emission type SEM (JEOL JSM-7001F). The step size for EBSD was $40 \mathrm{~nm}$. High-angle boundary structure on a longitudinal section of the sheet was constructed from the EBSD data. In the present study, boundaries having misorientation larger than $15^{\circ}$ are regarded as high-angle boundaries.

\section{Results and discussions}

Figure 2 shows the change in hardness of the specimens 1c, 3c, 5c and 7c after annealing. The hardness of the starting material (before ARB processing) was $47 \mathrm{HV}$, indicated by a broken line in the figure. After ARB processing, hardness increased to 79, 87, 98, and $102 \mathrm{HV}$ for the specimens $1 \mathrm{c}, 3 \mathrm{c}, 5 \mathrm{c}$, and 7c, respectively. As the annealing temperature increased above $100{ }^{\circ} \mathrm{C}$, hardness gradually decreased down to $47 \mathrm{HV}$. The specimen $7 \mathrm{c}$ was considered to be completely recrystallized at $350{ }^{\circ} \mathrm{C}$, as the hardness reached $47 \mathrm{HV}$ at this temperature.

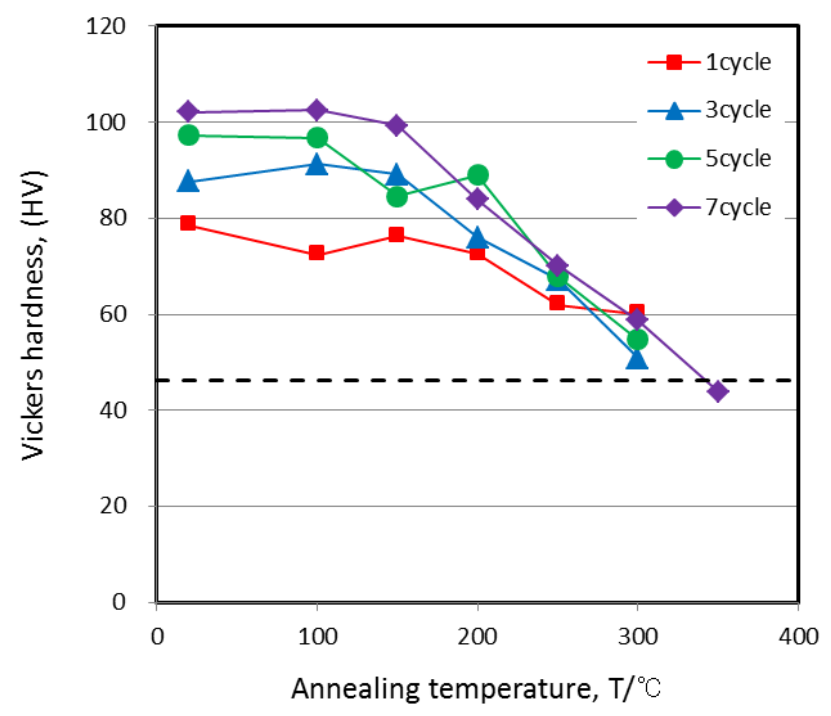

Fig. 2 Change in hardness of the specimens $1 \mathrm{c}, 3 \mathrm{c}, 5 \mathrm{c}$, and $7 \mathrm{c}$ annealed at temperatures ranging from 100 to $300{ }^{\circ} \mathrm{C}$. The specimen $7 \mathrm{c}$ was annealed at $350{ }^{\circ} \mathrm{C}$ as well. A broken line indicates the hardness of the starting material before ARB processing.

Figure 3 shows high angle boundary structures of the specimens 7c (as ARB-processed), 7c-200, and 7c-300 (i.e., as annealed at 200 and $300{ }^{\circ} \mathrm{C}$, respectively) obtained by the EBSD analysis. As shown in Fig. 3(c), the structure of the specimen 7c-300 was composed of both fine and coarse grains. The grain size distribution indicated two peaks, with average values of $1.7 \mu \mathrm{m}$ for the fine grains and $9.6 \mu \mathrm{m}$ for the coarse grains. By comparing Fig. 3 (b) with Figs. 3(a) 
and (c), it is found that the specimen 7c-200 is not recrystallized, but only recovered; this is indicated by the grains of specimen 7c-200 maintaining a pancake shape similar to those in the specimen 7c. The pancake-shaped grains had a high aspect-ratio of more than 8 . Therefore, instead of the grain diameter, the grain boundary spacing along the normal direction of the sheet was evaluated by an intersection method. The specimen 7c-200 had almost the same grain boundary spacing as the specimen $7 \mathrm{c}$; these were $0.26 \mu \mathrm{m}$ for the specimen $7 \mathrm{c}$ and $0.29 \mu \mathrm{m}$ for the specimen $7 \mathrm{c}-200$.

(a) Specimen 7c

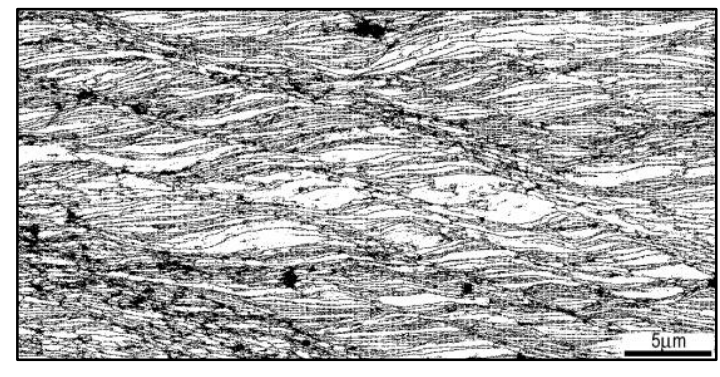

(b) Specimen $7 \mathrm{c}-200$

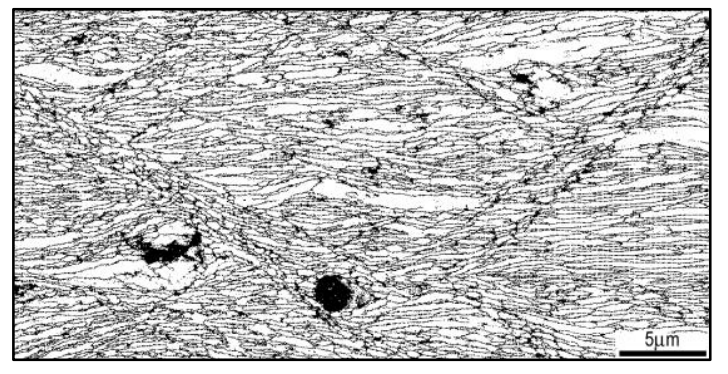

(c) Specimen 7c-300

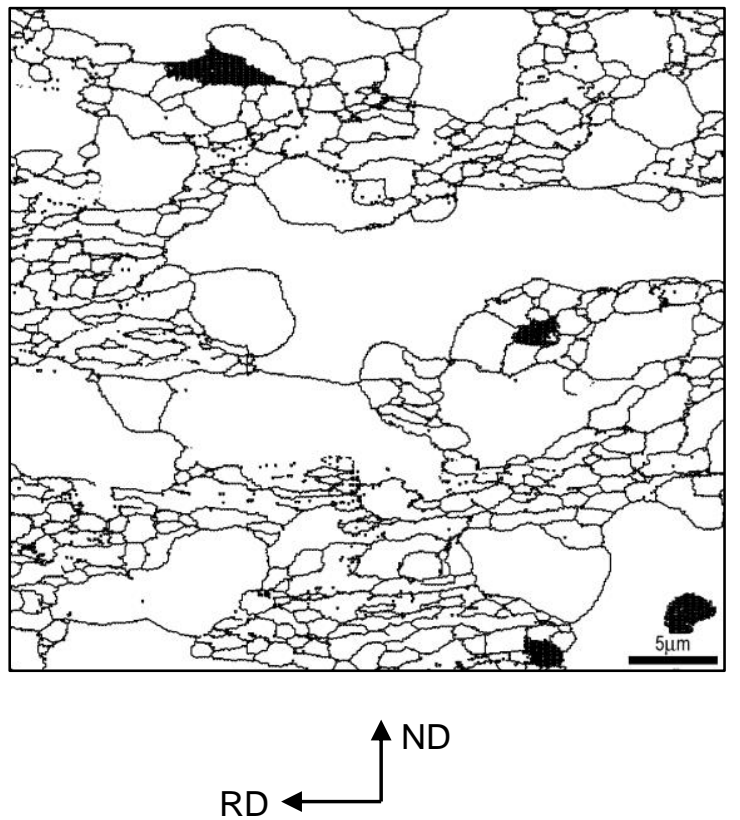

Fig. 3 Grain boundary maps showing high angle boundary structures measured by the EBSD method for the specimen $7 \mathrm{c}$ (a), and specimen $7 \mathrm{c}$ as annealed at $200{ }^{\circ} \mathrm{C}$ (b) and $300{ }^{\circ} \mathrm{C}$ (c). The observation plane was a longitudinal section of the sheet. The symbols "RD" and "ND" mean the rolling direction and the normal direction, respectively.

Figure 4 shows stress-strain curves for specimens annealed at various temperatures after conducting ARB from 1 to 7 cycles. Those of as-ARB-processed specimens and starting material specimens were also indicated. Compared with Figs. 4 (a) to (d), the tensile strength in as-ARB-processed specimen increased, while the total elongation decreased, as the number of ARB cycle increased. The highest tensile strength and the lowest total elongation were obtained in the specimen 7c, which were $422.9 \mathrm{MPa}$ and $1.2 \%$, respectively. Paying attention to the annealed specimens, tensile strength decreased and total elongation increased as the annealing temperature increased in each figure.

Figure 5 shows the relationship between $0.2 \%$ proof stress and uniform elongation in as-ARB-processed specimens (denoted "as ARBed" in the figure legend, and by their cycle number, e.g., $3 c$ ), and in specimens annealed after 1-7 cycles of ARB ( " $1 c, 3 c, 5 c$, and $7 c$ annealed," and designated further by the annealing temperature as, e.g., 1c-100).

In the as-ARB-processed specimens, i.e. the specimens $1 \mathrm{c}, 3 \mathrm{c}, 5 \mathrm{c}$, and $7 \mathrm{c}$, the uniform elongation decreased as the $0.2 \%$ proof stress increased. This result is consistent with that reported in previous studies on aluminum alloys (Lee, et al., 2002) (Toroghinejad, et al., 2013).

The curve for the specimens subjected to 1 ARB cycle and then annealed (red line) overlapped with that for the as-ARB-processed specimen (black line). Considering only annealed specimens, the uniform elongations for the annealed specimens processed by 3 or more ARB cycles were larger than those for the annealed specimens with 1 ARB cycle, even though they had nearly the same value of $0.2 \%$ proof stress. For example, the uniform elongation of the specimen $1 \mathrm{c}-100,3 \mathrm{c}-200$, and $7 \mathrm{c}-250$ was $3.1 \%, 5.3 \%$, and $10.8 \%$, respectively, although these specimens had almost the same $0.2 \%$ proof stress of about $260 \mathrm{MPa}$. It should be emphasized that larger uniform elongation after annealing was obtained as the number of ARB cycles increased. 
This result clearly indicates that the uniform elongation after annealing is affected by the degree of strain imposed by ARB. The reason for the improvement of uniform elongation can be explained using a mechanism reported by Tsuji et al. (Tsuji et al., 2002). They conducted ARB and annealing experiments using A1100 and IF steel, and observed that dislocations stored inside ultra-fine grains during ARB processing increased the flow stress, but decreased the work hardening rate $(d \sigma / d \varepsilon)$. The decrease of work hardening rate led to plastic instability at an early stage in tensile tests and limited the uniform elongation to a low value. This mechanism implies that the uniform elongation would be improved if dislocations inside ultra-fine grains are annihilated by low-temperature annealing.
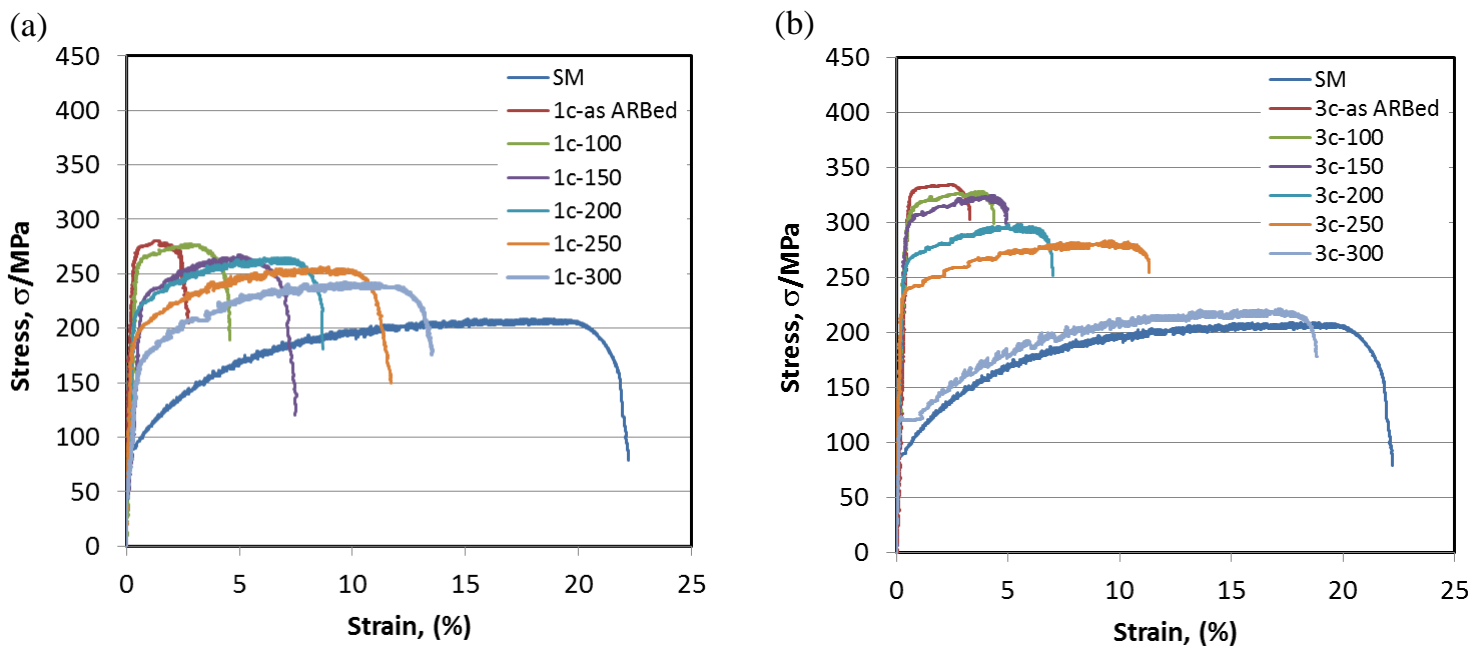

(c)
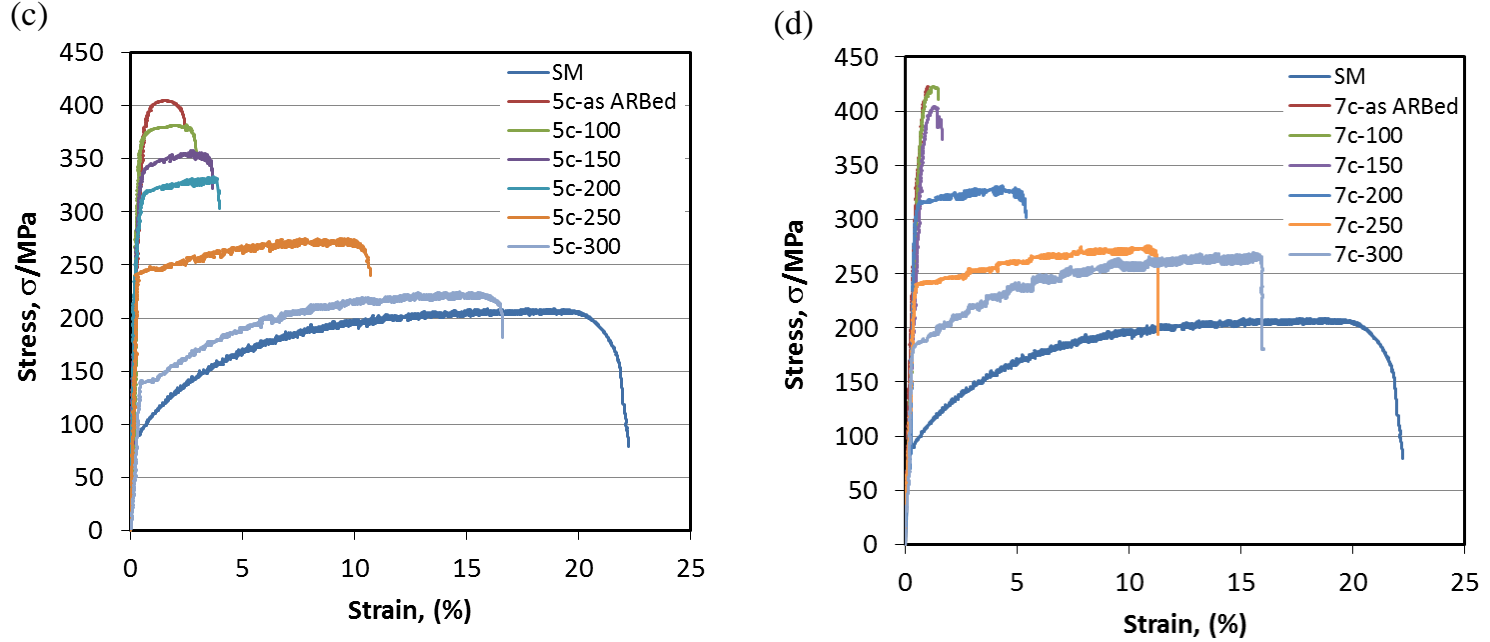

Fig. 4 Stress-strain curves for specimens annealed at 100, 150, 200, 250, and $300^{\circ} \mathrm{C}$ after $\mathrm{ARB}$ for (a) 1 cycle, (b) 3 cycles, (c) 5 cycles, and (d) 7 cycles. Stress-strain curves for starting material and as-ARB-processed specimen are also indicated. The symbol "SM" means the starting material before ARB.

It is well known that the grain size decreases with increasing the number of ARB cycle. (Pirgazi et al., 2008). During ARB process in Al-Mg alloy system, the strength of alloy is enhanced by grain refinement and dislocations stored inside grains, of which effects are classified as the grain boundary strengthening and the dislocation strengthening, respectively.

In our previous study (Kashihara et al., 2015), A5052 alloy sheets were deformed by ARB to 7cycles, and then annealed at various temperatures. The tensile properties of the specimen processed by 3 cycles of ARB (denoted as "the specimen $3 c$ ") were compared with those of the specimen annealed at $200{ }^{\circ} \mathrm{C}$ followed by 7 cycles of ARB (denoted as 
"the specimen 7c-200"). These two specimens showed the same $0.2 \%$ proof stress at about $325 \mathrm{MPa}$, but the specimen $3 \mathrm{c}$ had a smaller uniform elongation than the specimen 7c-200. The boundary spacing, which affects the grain boundary strengthening, was $0.65 \mu \mathrm{m}$ in the specimen $3 \mathrm{c}$ and $0.29 \mu \mathrm{m}$ in the specimen $7 \mathrm{c}-200$. Since $0.2 \%$ proof stress in the two specimens was identical, it was obvious that the effect of dislocation strengthening was stronger in the specimen $3 \mathrm{c}$, and the effect of grain boundary strengthening was stronger in the specimen 7c-200. The larger uniform elongation in the specimen 7c-200 is ascribed to less occurrence of plastic instability in the tensile test. As mentioned above, the plastic instability in tensile test is caused by the dislocations stored inside ultra-fine grains.

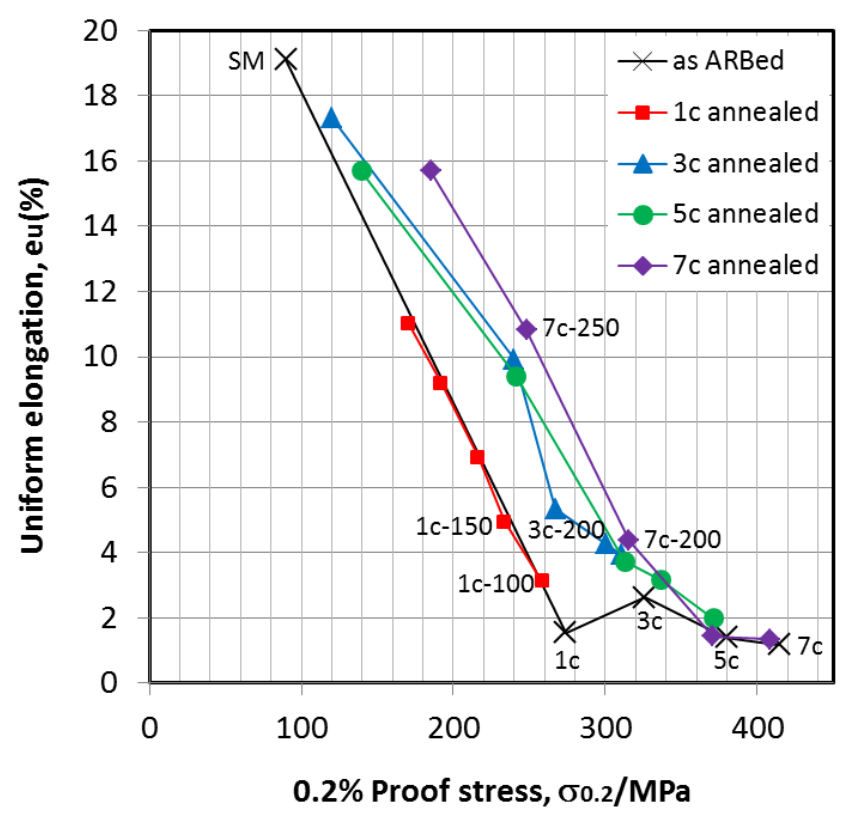

Fig. 5 Uniform elongation of the ARB-processed and annealed specimens as a function of $0.2 \%$ proof stress. As-ARB-processed specimens and annealed specimens are denoted as "as ARBed" and as "1c, 3c, 5c, and 7c annealed," respectively. The symbol "SM" means the starting material before ARB.

In this study, there is no data on the grain boundary spacing, but based on our previous study (Kashihara et al., 2015), the specimen 7c would have the smallest spacing, the specimen $3 \mathrm{c}$ the second smallest spacing, and then the specimen 1c the third. After the specimens 1c, 3c, and 7c were annealed at 100, 200, and $250{ }^{\circ} \mathrm{C}$, respectively, the different amounts of uniform elongation were observed in the specimens 1c-100, 3c-200, and 7c-250, while the $0.2 \%$ proof stresses were almost the same. The result of hardness tests in Fig. 2 would show that the specimens $1 \mathrm{c}-100$ and $3 \mathrm{c}-200$ have probably recovered structures after the annealing at 100 and $200{ }^{\circ} \mathrm{C}$, respectively. It is speculated from Figs. 3 (b) and (c) that the specimen 7c-250 has an intermediate grain structure between the specimen 7c-200 and the specimen 7c-300, consisting of recovered and partially recrystallized grains. The effect of dislocation strengthening in the specimen $7 c-250$ would be relatively the smallest among the three specimens. Therefore, the uniform elongation is considered to be largest in the specimen $7 \mathrm{c}-250$ because of less occurrence of plastic instability.

Finally, we discuss why larger uniform elongation after low-temperature annealing is obtained as the number of ARB cycle increases. During recovery stage in annealing, a lot of dislocations stored inside grains move, and two signs (plus and minus) of dislocations are removed by annihilation (Humphreys and Hatherly, 1996). The remaining excess dislocations inside grains will arrange into low angle boundaries. As the grain size becomes smaller and smaller, moving dislocations are easily absorbed by grain boundaries and the annihilation of dislocations inside the grains is facilitated. In a specimen with very small grain size such as the specimen $7 \mathrm{c}$ in this study, the annihilation of dislocations in low-temperature annealing would be facilitated, and the plastic instability in tensile test would be much less likely to occur. The degree of plastic instability is considered to change depending on the size of submicron scale grains. Smaller grains formed by ARB cause less plastic instability in tensile test after annealing. This is a possible 
reason why the higher strain imposed in the ARB process resulted in the higher elongation after low-temperature annealing in this study.

As shown in Figs. 3 (a) and (b), the specimens 7c and 7c-200 had almost the same grain boundary spacing. In Fig. 5 , the $0.2 \%$ proof stresses for the specimens $7 \mathrm{c}$ and $7 \mathrm{c}-200$ were $\sigma_{0.2}=414.3$ and $315.6 \mathrm{MPa}$, respectively. The reduction in the specimen $7 \mathrm{c}-200$ after annealing was $98.7 \mathrm{MPa}$. The uniform elongations for the specimens $7 \mathrm{c}$ and $7 \mathrm{c}-200$ were $e_{u}=1.2$ and $4.4 \%$, respectively. The increase in the specimen7c-200 was $3.2 \%$. The reduction in proof stress and increase in elongation for the specimen $7 \mathrm{c}-200$ were caused by the annihilation of dislocations inside the ultra-fine grains during annealing, while the grain size remained roughly the same as that in the specimen $7 \mathrm{c}$. The $0.2 \%$ proof stress value for the specimen 7c-200 was higher than that for the specimen 1c-150, showing an enhancement with increasing the number of ARB cycle, although both have the same uniform elongation (4.9\%).

\section{Conclusions}

Sheets of an A5052 alloy were ARB-processed by 1, 3, 5 and 7 cycles and then annealed at temperatures ranging from 100 to $300{ }^{\circ} \mathrm{C}$ for $30 \mathrm{~min}$. The relationship between the uniform elongation and the $0.2 \%$ proof stress was examined. The uniform elongation after annealing was affected by the degree of strain imposed by ARB. The higher strain in the ARB process resulted in the higher elongation after low-temperature annealing. The uniform elongation of the ARB-processed specimens was improved by low-temperature annealing below $300{ }^{\circ} \mathrm{C}$, when the specimens were processed by 3 or more cycles of ARB. This result would be useful for the fabrication of Al-Mg alloy sheets having good balance of high strength and good formability.

\section{Acknowledgements}

This work was conducted in the Research Division of Preferred Orientations Control through Plastic Deformation and Heat Treatment, Japan Institute of Light Metals. K.K. acknowledges financial support from the Light Metal Educational Foundation, Inc. and technical help by S. Yamamoto. N.T. thanks the Grant-in-Aid for Scientific Research on Innovative Area, "Bulk Nanostructured Metals", from the Ministry of Education, Culture, Sports, Science and Technology of Japan for their support.

\section{References}

Abdulov, R. Z., Valiev, R. Z., Krasilnikov, N. A., Formation of submicrometre-grained structure in magnesium alloy due to high plastic strains, Journal of Materials Science Letters, Vol.9, (1990), pp.1445-1447.

Furukawa, M., Horita, Z., Nemoto, M., Valiev, R. Z. and Langdon, T. G., Microhardness measurments and the Hall-Petch relationship in an Al-Mg alloy with submicrometer grain size, Acta Materialia, Vol.44, (1996), pp.4619-4629.

Humphreys, F. J. and Hatherly, M., Recrystallization and Related Annealing Phenomena (1996), p.144, Pergamon.

Kashihara, K., Komi, Y., Terada, D. and Tsuji, N., Improvement of uniform elongation by low temperature annealing in Al-2.5\% Mg alloy processed by accumulative roll bonding, Materials Transactions, Vol.56, No.6 (2015), pp.803807.

Lee, S. H., Saito, Y., Sakai, T. and Utsunomiya, H., Microstructures and mechanical properties of 6061 aluminum alloy processed by accumulative roll-bonding, Materials Science and Engineering A, Vol.325, (2002), pp.228-235.

Pirgazi, H., Akbarzadeh, A., Petrov, R. and Kestens, L., Microstructure evolution and mechanical properties of AA1100 aluminum sheet processed by accumulative roll bonding, Materials Science and Engineering A, Vol.497, (2008), 132-138.

Richert, M. and Korbel, A., The effect of alloying on the mechanical performance and substructure of aluminum at large strains, Materials Science and Engineering A, Vol.234-236, (1997), pp.908-911.

Richert, M., Liu, Q. and Hansen, N., Microstructural evolution over a large strain range in aluminum deformed by cyclic-extrusion-compression, Materials Science and Engineering A, Vol.260, (1999), pp.275-283.

Saito, Y., Utsunomiya, H., Tsuji, N. and Sakai, T., Novel ultra-high straining process for bulk materials - Development of the accumulative roll-bonding (ARB) process, Acta Materialia, Vol.47, No.2 (1999), pp.579-583. 
Toroghinejad, M. R., Ashrafizadeh, F. and Jamaati, R., On the use of accumulative roll bonding process to develop nanostructured aluminum alloy 5083, Materials Science and Engineering A, Vol.561, (2013), pp.145-154.

Tsuji, N., Shiotsuki, K. and Saito, Y., Superplasticity of ultra-fine grained Al-Mg alloy produced by accumulative roll-bonding, Materials Transactions, JIM, Vol.40, No.8 (1999), pp.765-771.

Tsuji, N., Ito, Y., Saito, Y. and Minamino, Y., Strength and ductility of ultrafine grained aluminum and iron produced by ARB and annealing, Scripta Materialia, Vol.47, (2002), pp.893-899.

Valiev, R. Z., Krasilnikov, N. A. and Tsenev, N. K., Plastic deformation of alloys with submicron-grained structure, Materials Science and Engineering A, Vol.137, (1991), pp.35-40.

Zhilyaev, A. P., Oh-ishi, K., Langdon, T. G. and McNelley, T. R., Microstructural evolution in commercial purity aluminum during high-pressure torsion, Materials Science and Engineering A, Vol.410-411, (2005), pp.277-280. 